\title{
Performance Estimation of LCL-T Resonant Converter with Fuzzy/ PID Controller Using State Space Analysis
}

\author{
${ }^{1}$ C.Nagarajan, Member,IEEE, IACSIT and ${ }^{2}$ M.Madheswaran, Member, IEEE
}

\begin{abstract}
This paper presents a comparative evaluation of Proportional Integral Derivative (PID) Controller and Fuzzy Logic Controller (FLC) for a modified LCL-T (inductor capacitor inductor) Series Parallel Resonant Converter (SPRC) has been simulated and the performance is analysised. A three element LCL-T SPRC working under load independent operation (voltage type and current type load) is presented in this paper. The analysis is carried out using the state space approach and the regulation of output voltage is done by using Fuzzy controller and PID Controller. The simulation study indicates the superiority of fuzzy control over the conventional control methods. The MATLAB simulated results show that the output of converter is free from the ripples, constant current, regulated output voltage and these converters can be used for many airborne applications.
\end{abstract}

Index Terms-Resonant Converter, Fuzzy logic, PID, Control System, MAT LAB, Power Electronics.

\section{INTRODUCTION}

In recent years the design and development of various DC-DC Resonant Converters (RC) have been focused for telecommunication and aerospace applications. It has been found that these converters experience high switching losses, reduced reliability, electromagnetic interference (EMI) and acoustic noise at high frequencies. The Series Parallel Resonant Converters (SPRC) are found to be suitable, due to various inherent advantages. The series and parallel Resonant Converter (SRC and PRC respectively) circuits are the basic resonant converter topologies with two reactive elements. The merits of SRC include better load efficiency and inherent dc blocking of the isolation transformer due to the series capacitor in the resonant network. However, the load regulation is poor and output-voltage regulation at no load is not possible by switching frequency variations. On the other hand, PRC offers no-load regulation but suffers from poor load efficiency and lack of dc blocking for the isolation transformer. Its has been suggested to design Resonant Converter with three reactive components for better regulation. The LCL tank circuit based DC-DC Resonant Converter has been experimentally demonstrated and

${ }^{1}$ C.Nagarajan, is the Research Scholar, Bharath University, Chennai Tamilnadu, India ,e-mail:.nagaraj2k1@yahoo com.

${ }^{2}$ M.Madheswaran, is with Department of Electronics and communication Engineering, Muthayammal Engineering College, Rasipuram, Tamilnadu, 637408,India.madheswaran.dr@gmail.com reported by many researchers [1]-[7]. Raju et al, has experimentally demonstrated with independent load when operated at resonant frequency, making it attractive for application as a constant voltage (CV) power supply. It has been found

from the literature that the LCL tank circuit connected in series-parallel with the load and operated in above resonant frequency improves the load efficiency and independent operation [3].

Later, Mangesh Borage et al [4], have demonstrated an LCL-T half bridge resonant converter with clamp diodes. The output current or voltage is sensed for every change in load because the output voltage or constant current increases linearly. The feed back control circuit has not been provided. LCL-T RC with constant current supply operated at resonant frequency is presented [5].The parallel operation is simple without any complex control circuit which increases to ripple frequency. Paolo Mattavelli [6] has demonstrated different approaches which offer the fuzzy logic control (FLC). This control technique relies on the human capability to understand the system's behavior and is based on qualitative control rules. The FLC approach with same control rules can be applied to several dc-dc converters. However, some scale factors must be tuned according to converter topology and parameters. The author utilized the proposed control technique for Buck-Boost converter and demonstrated. J.M. Correa et al [7] have demonstrated a DC/AC series resonant converter with fixed load value considering two control approaches. Later T.S.Sivakumaran et al [8] have demonstrated a CLC SPRC using FLC for load regulation and line regulation. The performance of controller has been evaluated and found that the load independent operation may not be possible. The FLC based Zero Voltage Switching quasi-resonant converter has been demonstrated by et al [9],10].The load independent operation was not realized and power handling capacity of the converter is found to be poor.

It is clear from the above literatures that the output voltage regulation of the converter against load and supply voltage fluctuations have important role in designing high-density power supplies. LCL-T SPRC is expected the speed of response, voltage regulation and better load independent operation. Keep the above facts in view, the LCL-T SPRC has been module and analysised for estimating various responses. The closed loop state space module has been derived and simulate using MAT LAB/Simulink for comparing the performance with existing converter. 


\section{Proposed LCL-T SERIES PARALlel RESONANT CONVERTER WiTH FUZZY/PID CONTROL CIRCUIT}

The block diagram of LCL-T SPRC with Fuzzy controller is shown in fig.1. The resonant tank consisting of three reactive energy storage elements (LCL-T) has overcome the conventional resonant converter that has only two elements. The first stage converts a dc voltage to a high frequency ac voltage. The second stage of the converter is to convert the ac power to dc power by suitable high frequency rectifier and filter circuit. Power from the resonant circuit is taken either through a transformer in series with the resonant circuit or series in the capacitor comprising the resonant circuit. In both cases the high frequency feature of the link allows the use of a high frequency transformer to provide voltage transformation and ohmic isolation between the dc source and the load.

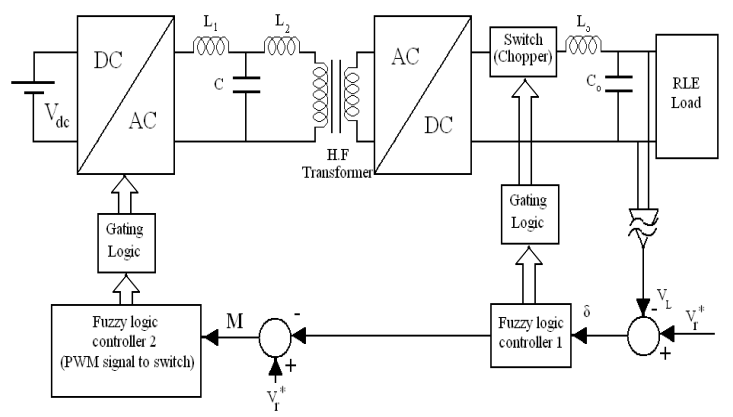

Fig.1 Block Diagram of LCL-T Series Parallel Resonant Converter

In LCL-T SPRC the load voltage can be controlled by varying the switching frequency or by varying the phase difference between the inverters. The phase domain control scheme is suitable for wide variation of load condition because the output voltage is independent of load. The dc current is absent in the primary side of the transformer, there is no possibility of current balancing. Another advantage of this circuit is that the device currents are proportional to load current. This increases the efficiency of the converter at light loads to some extent because the device losses also decrease with the load current. If the load gets short at this condition, very large current would flow through the circuit. This may damage the switching devices. To make the circuit short circuit proof, the operating frequency should be changed.

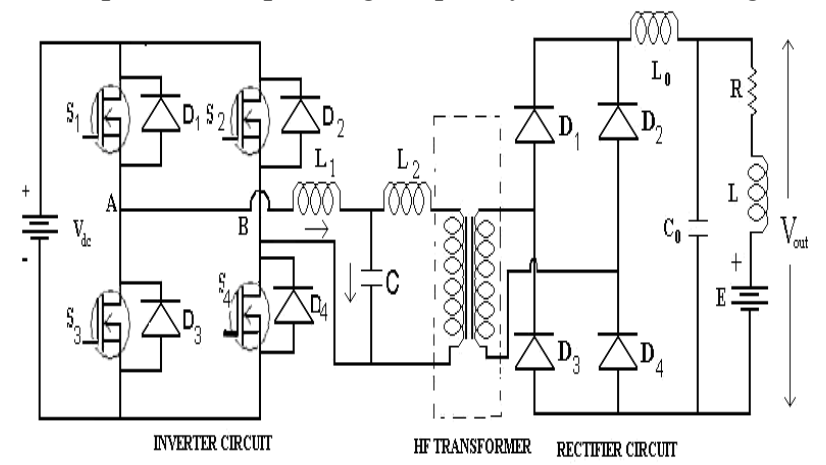

Fig.2. LCL-T SPRC Resonant Converter.

A schematic diagram of full-bridge LCL-T SPRC is shown in Fig.2. The resonant circuit consist of series inductance $L_{1}$, parallel capacitor $\mathrm{C}$ and series inductance $\mathrm{L}_{2}$. S1-S4 are switching devices having base /gate turn-on and turn-off capability. D1 to D4 are anti-parallel diodes across these switching devices. The MOSFET (say S1) and its anti parallel diode (D1) act as a bidirectional switch. The gate pulses for S1 and S2 are in phase but 180 degree out of phase with the gate pulses for S3 and S4. The positive portion of switch current flows through the MOSFET and negative portion flows through the anti-parallel diode. The RLE load is connected across bridge rectifier via $\mathrm{L}_{0}$ and $\mathrm{C}_{0}$. The voltage across the point $\mathrm{AB}$ is rectified and fed to RLE load through $\mathrm{L}_{0}$ and $\mathrm{C}_{0}$. In the analysis that follows, it is assumed that the converter operates in the continuous conduction mode and the semiconductors have ideal characteristics.

\section{Mathematical Modeling Using State Space TECHNIQUE}

The equivalent circuit of LCL-T SPRC is shown in Fig.3.the mathematical modeling using state space technique can be obtained assuming all the components to be ideal.

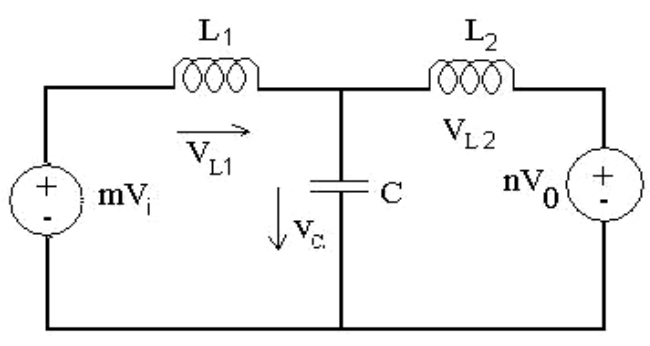

Fig.3 Equivalent Circuit Model of LCL - T SPRC

The vector space equation for the converter is given by

$$
\dot{X}=A X+B U
$$

Where

$$
\dot{X}=\frac{d}{d t}\left[\begin{array}{l}
i_{L 1} \\
V_{C} \\
i_{L 2}
\end{array}\right], \quad X=\left[\begin{array}{c}
i_{L 1} \\
V_{C} \\
i_{L 2}
\end{array}\right], \quad U=\left[\begin{array}{c}
V_{i} \\
V_{0}
\end{array}\right],
$$

The state space equation can be obtained from the Fig.3.the state equation for LCL-T SPRC converter is obtained as

$$
\begin{aligned}
\frac{d i_{L 1}}{d t} & =\frac{m V_{i}}{L_{1}}-\frac{V_{C}}{L_{1}} \\
\frac{d V_{C}}{d t} & =\frac{1}{C}\left(i_{L 1}-i_{L 2}\right) \\
\frac{d i_{L 2}}{d t} & =\frac{-n V_{o}}{L_{2}}+\frac{V_{C}}{L_{2}}
\end{aligned}
$$

Where

$$
A=\left[\begin{array}{ccc}
0 & \frac{-1}{L_{1}} & 0 \\
\frac{1}{C} & 0 & \frac{-1}{C} \\
0 & \frac{1}{L_{2}} & 0
\end{array}\right], \quad B=\left[\begin{array}{cc}
\frac{m}{L_{1}} & 0 \\
0 & 0 \\
0 & \frac{-n}{L_{2}}
\end{array}\right],
$$

The equation (1) can be written as 
$\frac{d}{d t}\left[\begin{array}{c}i_{L 1} \\ V_{C} \\ i_{L 2}\end{array}\right]=\left[\begin{array}{ccc}0 & \frac{-1}{L_{1}} & 0 \\ \frac{1}{C} & 0 & \frac{-1}{C} \\ 0 & \frac{1}{L_{2}} & 0\end{array}\right]\left[\begin{array}{c}i_{L 1}(t) \\ V_{C}(t) \\ i_{L 2}(t)\end{array}\right]+\left[\begin{array}{cc}\frac{m}{L 1} & 0 \\ 0 & 0 \\ 0 & \frac{-n}{L_{1}}\end{array}\right]\left[\begin{array}{c}V_{i} \\ V_{0}\end{array}\right]$

The sum of the zero input response and the zero state response is given by

$$
\begin{gathered}
X(t)=[\phi(t)[X(0)]]+L^{-1}[\phi(s) B[U(s)]] \\
{\left[\begin{array}{l}
i_{L 1} \\
V_{C} \\
i_{L 2}
\end{array}\right]=\left[\begin{array}{ccc}
\cos \omega t+\frac{1}{C L_{2} \omega^{2}}[1+\cos \omega t] & \frac{-1}{L_{1}} \sin \omega t & \frac{1}{C L_{1} \omega^{2}}[1+\cos \omega t] \\
\frac{-1}{C \omega}[\sin \omega t] & \cos \omega t & \frac{-1}{C \omega} \sin \omega t \\
\frac{1}{C L_{2} \omega^{2}}[1+\cos \omega t] & \frac{1}{L_{2} \omega} \sin \omega t & \cos \omega t+\frac{1}{C L_{1} \omega^{2}}[1+\cos \omega t]
\end{array}\right]} \\
{\left[\begin{array}{c}
\left.i_{L 1}(t)\right] \\
V_{C}(t) \\
i_{L 2}(t)
\end{array}\right]+\left[\begin{array}{cc}
\frac{m}{L_{1}}\left[\frac{1}{\omega} \sin \omega t+\frac{1}{C L_{2} \omega^{2}}\left(t+\frac{1}{\omega} \sin \omega t\right)+\frac{m V_{i}^{2}}{C t}\left(t+\frac{1}{\omega} \sin \omega t\right)\right] \\
\frac{-1}{\omega C} \sin \omega t-\frac{m V_{0}}{L_{2}} \frac{1}{\omega} \sin \omega t \\
\frac{1}{\omega^{2} C L_{2} L} m L_{1}\left[1+\frac{1}{\omega} \sin \omega t\right]-\frac{n V_{0}}{L_{2}}\left[\frac{1}{\omega} \sin \omega t+\frac{1}{\omega^{2}}\left(t+\frac{\sin \omega t}{\omega}\right)\right]
\end{array}\right]}
\end{gathered}
$$

Consider

$I_{1}=\frac{m}{L_{1}}\left[\frac{1}{\omega} \sin \omega t+\frac{1}{C L_{2} \omega^{2}}\left(t+\frac{1}{\omega} \sin \omega t\right)+\frac{m V_{i}}{C L_{1}^{2}}\left(t+\frac{1}{\omega} \sin \omega t\right)\right]$

$$
I_{2}=\frac{-1}{\omega C} \sin \omega t-\frac{m V_{0}}{L_{2}} \frac{1}{\omega} \sin \omega t
$$

$$
\begin{aligned}
I_{3}= & \frac{1}{\omega^{2} C L_{2} L_{1}} m V_{i}\left[1+\frac{1}{\omega} \sin \omega t\right]-\frac{n V_{0}}{L_{2}}\left[\frac{1}{\omega} \sin \omega t+\right. \\
& \left.\frac{1}{\omega^{2}}\left(t+\frac{\sin \omega t}{\omega}\right)\right]
\end{aligned}
$$

And $t_{p-1}$ and $t_{p}$ are the time at the start and end of ccm.

From solving the equation (2) and (4) we get

$$
\begin{aligned}
& i_{L 1}(t)=i_{L 1}\left(t-t_{p-1}\right)\left[\cos \omega\left(t-t_{p-1}\right)+\right. \\
& \frac{1}{C L_{2} \omega^{2}}\left[1+\cos \omega\left(t-t_{p-1}\right)\right] I_{1}+ \\
& \left.\left[\frac{-1}{L_{1} \omega}\right) \sin \omega t\right]\left[V_{C}\left(t-t_{p-1}\right)\right] I_{2}+ \\
& {\left[\frac{1}{C L_{1} \omega^{2}}\right]\left(1+\cos \omega\left(t-t_{p-1}\right)\right)} \\
& \left(i_{L 2}\left(t-t_{p-1}\right)\right) I_{3}
\end{aligned}
$$

$V_{C}(t)=i_{L 1}\left(t-t_{p-1}\right)\left[\frac{-1}{C \omega} \sin \omega\left(t-t_{p-1}\right) I_{1} V_{C}\left(t-t_{p-1}\right) \cos \omega I_{2}\right.$ $+I_{L 2}\left(t-t_{p-1}\right)\left[\left(\frac{-1}{C \omega} \sin \omega\left(t-t_{p-1}\right)\right)\right] I_{3}$

$$
\begin{aligned}
& i_{2}(t)=i_{L 1}\left(t-t_{p-1}\right) \frac{1}{C L_{2} \omega^{2}}\left[1+\cos \omega\left(t-t_{p-1}\right)\right] I_{1} \\
& +V_{C}\left(t-t_{p-1}\right)\left[\left(\frac{1}{L_{2} \omega}\right) \sin \omega\left(t-t_{p-1}\right)\right] I_{2} \\
& +i_{L 2}\left(t-t_{p-1}\right)\left[\cos \omega\left(t-t_{p-1}\right)\right. \\
& +\left[\frac{1}{C L_{1} \omega^{2}}\right]\left(1+\cos \omega\left(t-t_{p-1}\right)\right) I_{3}
\end{aligned}
$$

The output voltage can be estimated from equation (8) (9) and (10).

\section{DESIGN OF FuZzy Logic / PID CONTROLlers}

\section{A. Fuzzy Logic Controllers}

The Fuzzy Logic Controller (FLC) provides an adaptive control for better system performance. Fuzzy logic is aimed to provide solution for controlling non-linear processes and to handle ambiguous and uncertain situations. Fuzzy control is based on the fundamental of fuzzy sets. The fuzzy control for the chosen SPRC is developed using input membership functions for error ' $e$ ' and change in error 'ce' and the output membership function for $\mathrm{D}$, the duty ratio of converter.

The fuzzy control scheme is described using a dc to dc converter as a platform. The Fig. 4 shows the block diagram of the fuzzy logic control configuration for a dc to $\mathrm{dc}$ converter. The output of the fuzzy control algorithm

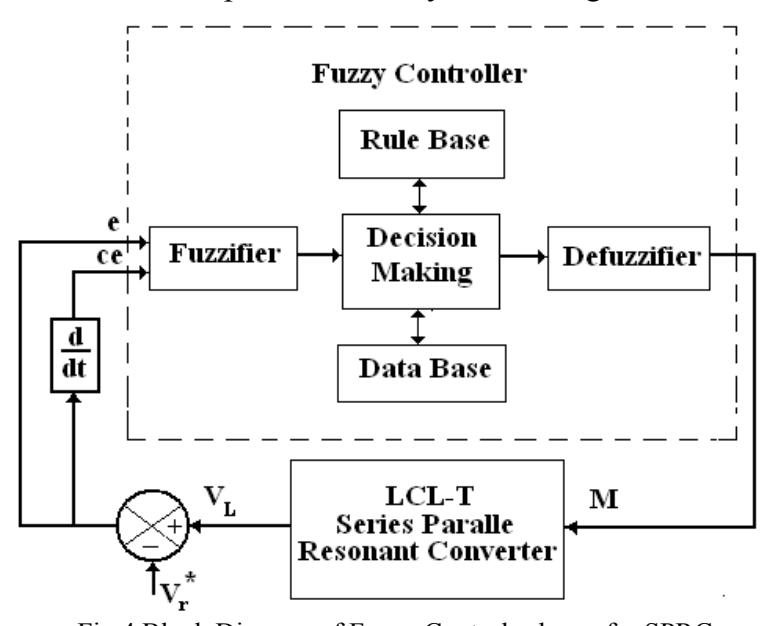

Fig.4 Block Diagram of Fuzzy Control scheme for SPRC

is the change in duty cycle $[\$ \mathrm{~d}(\mathrm{k})]$. The duty cycle $\mathrm{d}(\mathrm{k})$, at the $\mathrm{k}^{\text {th }}$ sampling time, is determined by adding the previous duty cycle $[\mathrm{d}(\mathrm{k}-1)]$ to the calculated change in duty cycle.

$$
\mathrm{d}(\mathrm{k})=\mathrm{d}(\mathrm{k}-1)+\$ \mathrm{~d}(\mathrm{k})
$$

\section{B. PID Controller \\ C. Controller Structure}

A standard PID controller is a three term controller, whose transfer function is generally written in the in the parallel form given by equation or the ideal form given by 


$$
\begin{aligned}
& G(s)=K_{P}+\frac{K_{I}}{S}+K_{D} S \\
& G(s)=K_{P}\left(1+\frac{1}{T_{I} S}+T_{D} S\right)
\end{aligned}
$$

- The proportional term-providing an overall control action proportional to the error signal through the all pass gain factor.

- The integral term-reducing steady state errors through low frequency compensation by an integrator.

- The derivative term-improving transient response through compensation by a differentiator.

\section{V. . Simulation of The Proposed System}

\section{A. A.Fuzzy Logic Control (FLC)}

Fuzzy control involves three stages: fuzzification, inference or rule evaluation and defuzzification as shown in Fig.4. SPRC is modeled using Matlab software (version 7.1). Fuzzy control is developed using the fuzzy toolbox. The fuzzy variables 'e', 'ce' and ' $\mathrm{D}$ ' are described by triangular membership functions. Five triangular membership functions are chosen for simplicity and Table I shows the fuzzy rule base created in the present work based on intuitive reasoning and experience. Fuzzy memberships NB, NS, Z, PS, PB are defined as negative big, negative small, zero and positive small, positive.

\section{B.Rule Table and Inference Engine}

The control rules that relate the fuzzy output to the fuzzy inputs are derived from general knowledge of the system behavior, perception and experience. The rule table for the designed fuzzy controller is given in the Table 1. The Graphical representations for the fuzzy rules are shown in Fig.6.
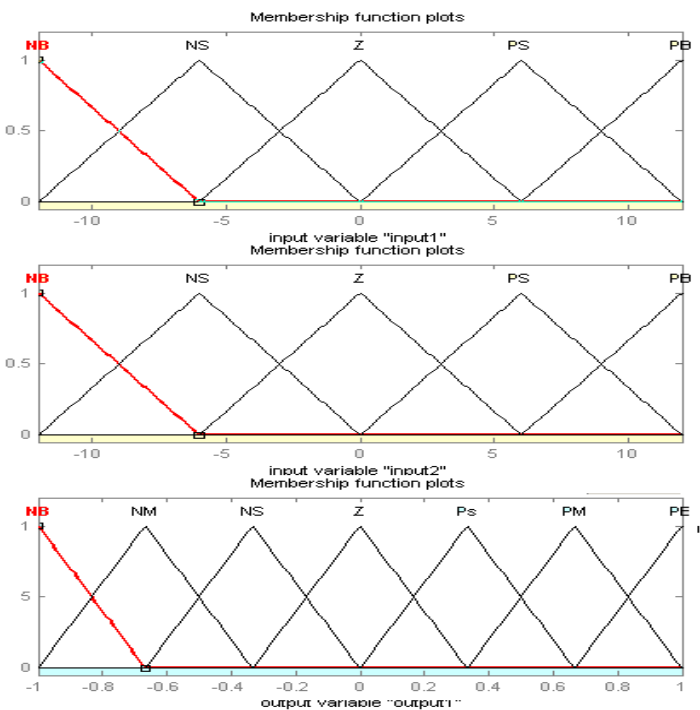

Fig .5 Fuzzy memberships used for simulation

- If the output voltage is far from the reference value, then the change of switching frequency must belarge so as to bring the output to the reference value quickly.

- If the output voltage approaches the reference value, then a small change of switching frequency is necessary.
- If the output voltage is near the reference value and is approaching it rapidly, then the frequency must be kept constant so as to prevent overshoot.

- If the output voltage changes even after reaching the reference value then the change of frequency must be changed by a small amount to prevent the output from moving away.

TABLE.I

\begin{tabular}{|c|c|c|c|c|c|c|}
\hline Err & & & & & & \\
\hline \multirow{6}{*}{ 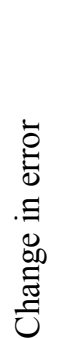 } & & NB & NS & $Z$ & PS & PB \\
\hline & NB & NB & NB & NB & NM & $\mathrm{Z}$ \\
\hline & NS & NB & NM & $\mathrm{NS}$ & $Z$ & $\mathrm{PM}$ \\
\hline & $Z$ & NB & NS & $Z$ & PS & PB \\
\hline & PS & $\mathrm{NM}$ & $Z$ & PS & PM & PB \\
\hline & PB & $\mathrm{Z}$ & PM & $\mathrm{PB}$ & PB & PB \\
\hline
\end{tabular}

Fuzzy Rules

\section{B. D.Development of the FLC}

At every sampling interval, the instantaneous RMS values of the sinusoidal reference voltage and load voltage are used to calculate the error (e) and change in error (ce) signals that act as the input to the FLC.The stage of fuzzification, fuzzy inference and defuzzification are then perform program as generally described in the flowchart of Fig.7.

$$
\begin{aligned}
& \mathrm{e}=\mathrm{Vr}-\mathrm{V}_{\mathrm{L}} \\
& \mathrm{ce}=\mathrm{e}-\mathrm{pe}
\end{aligned}
$$

Where $\mathrm{Vr}$ is the reference or the desired output voltage and $\mathrm{V}_{\mathrm{L}}$ is the actual output voltage. The subscript ' $\mathrm{k}$ ' denotes values at the beginning of kth sampling cycle.

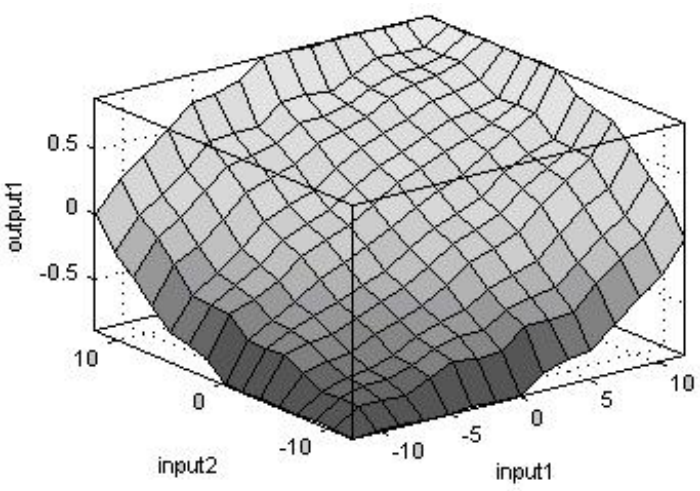

Fig.6 Graphic representation of Table I.

The duty ratio of the converter will be determined by the fuzzy inference. For instance, if the output voltage continues to increase gradually while the current is low during the charging process, the fuzzy controller will maintain the increase in voltage to reach the set point. A drop in the output voltage level triggers the fuzzy controller to increase the output voltage of the converter by modifying the duty cycle of the converter. The resolution of fuzzy logic control system relies on the fuzziness of the control variables while the fuzziness of the control variables depends on the fuzziness of their membership functions. 


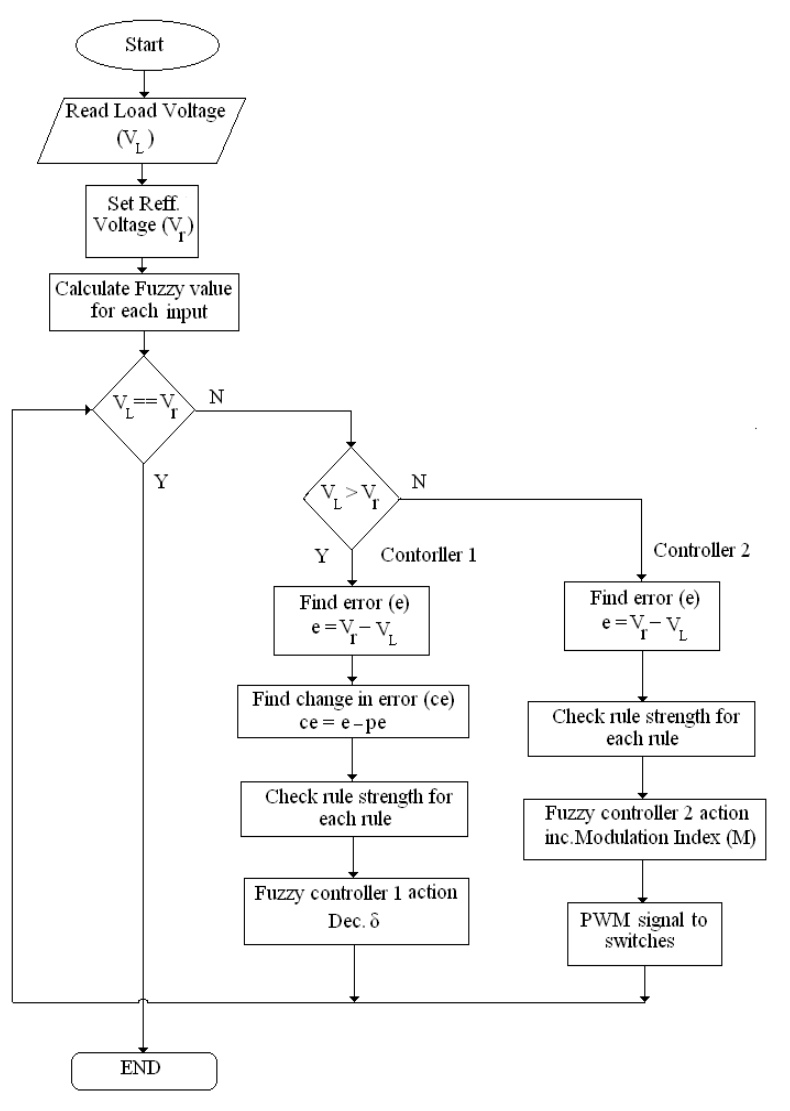

Fig.7 structure of the fuzzy controller for rectifier side.

The Closed loop simulation using FLC and PID controller for the SPRC is carried out using MATLAB/Simulink software. Depending on error and the change in error, the value of change of switching frequency is calculated. Set parameter instruction and function blocks available in MATLAB are used to update the new switching frequency of the pulse generators. Fig.8.shows that the generated pulses form the FLC that's to be given to the inverter circuit.

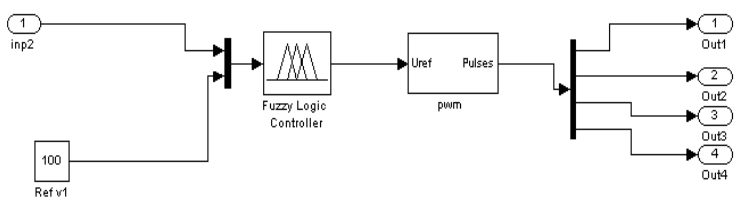

Fig.8 structure of the fuzzy controller for inverter side

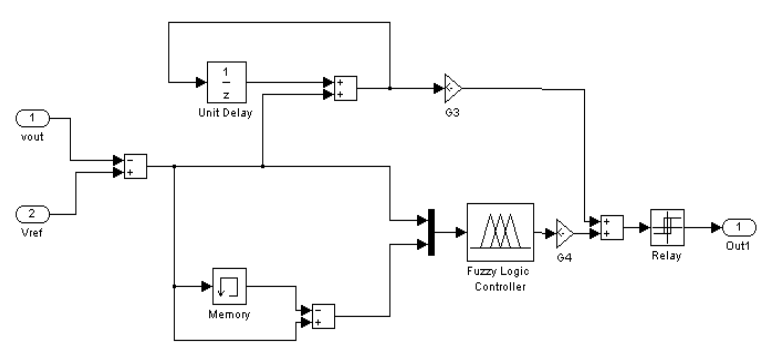

Fig.9 structure of the fuzzy controller for rectifier side

The closed loop Simulink diagram of LCL-T SPRC using FLC is shown in Fig.10. The entire system is simulated with a switching frequency of $100 \mathrm{KHz}$. The simulated converter output voltage $\mathrm{V}_{\mathrm{o}}$ and load current $\mathrm{I}_{\mathrm{o}}$ for a step change in load from 0.4 to 0.5 its applied at 10 milliseconds. It is observed that the FLC for LCL-T SPRC regulates the output voltage with a settling time of 0.07 millisecond.

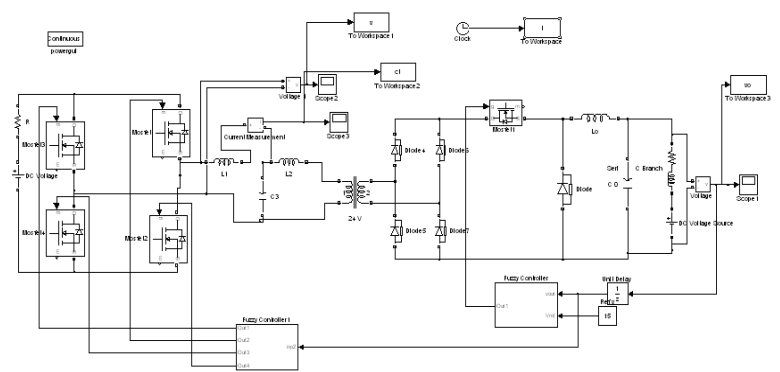

Fig.10 Simulink Model of the proposed FLC system.

\section{E.PID controller}

Controllers based on the PID approach are commonly used for DC-DC converter applications. Power converters have relatively low order dynamics that can be well controlled by the PID method.

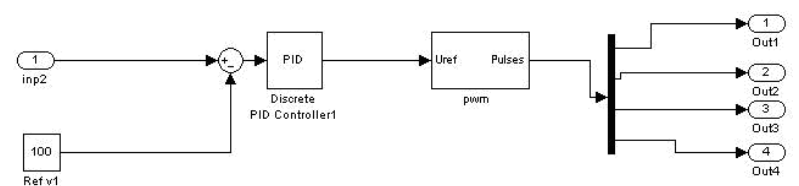

Fig.11 structure of the PID controller for inverter side

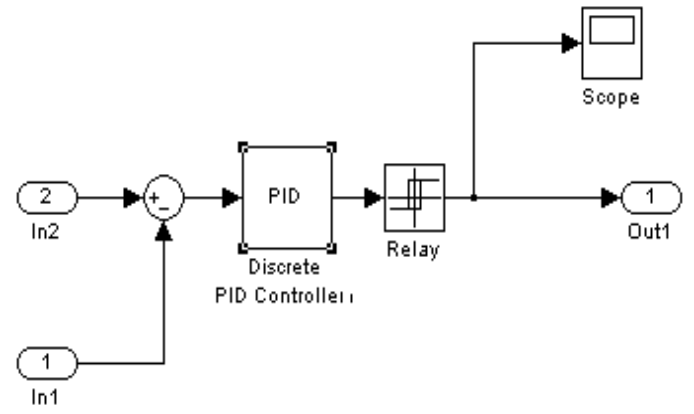

Fig. 12 structure of the PID controller for rectifier side

PID based closed loop Simulink diagram of LCL-T SPRC is shown in Fig.13. The system is simulated with a switching frequency of $100 \mathrm{KHz}$. The simulated converter output voltage $V_{o}$ and load current $I_{o}$ for applied at 10 milliseconds. It is observed that the PID for LCL-T SPRC regulates the output voltage with a settling time of 0.1 millisecond.

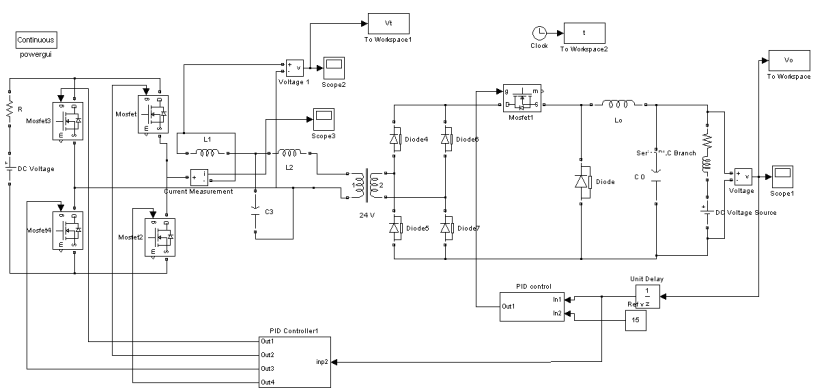

Fig.13 Simulink Model of the proposed PID system

\section{ViI.RESUlts AND DisCUSSION}

The proposed model has been simulated using MATLAB/Simulink toolbox. The fuzzy controller and PID controller has been designed for LCL-T SPRC. The simulated wave forms of resonant voltage, resonant current, Output Voltage, and output Current are shown in Fig 14-24. 
The fuzzy controller performance was also compared with the PID controller performance for the converter.

\section{A. Open Loop Response}

The response for a reference voltage of $10 \mathrm{~V}$ and output voltage is $12 \mathrm{~V}$, in the open loop response, the overshoot and the settling time are very high, and the response is oscillatory. The proposed control strategy is able to eliminate the peak overshoot and reduce the settling time. The resonant voltage, resonant current and output voltage are shown in fig. with different load variation $\mathrm{R}_{\mathrm{L}}(50 \%$ \& $100 \%$,), and RLE. The voltage across $\mathrm{V}_{\mathrm{AB}}$ and primary current of the transformer are shown in fig.14-15.
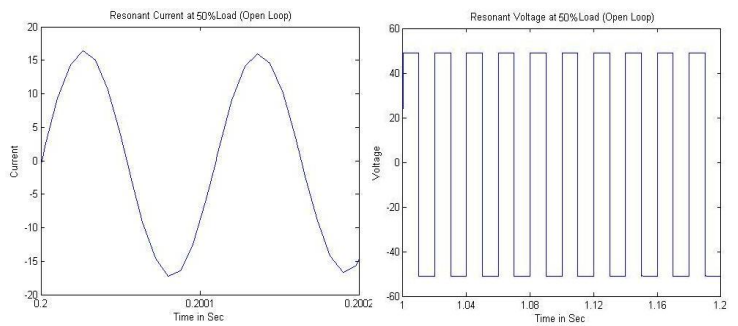

Fig.14 Resonant current and resonant voltage at $50 \%$ of load

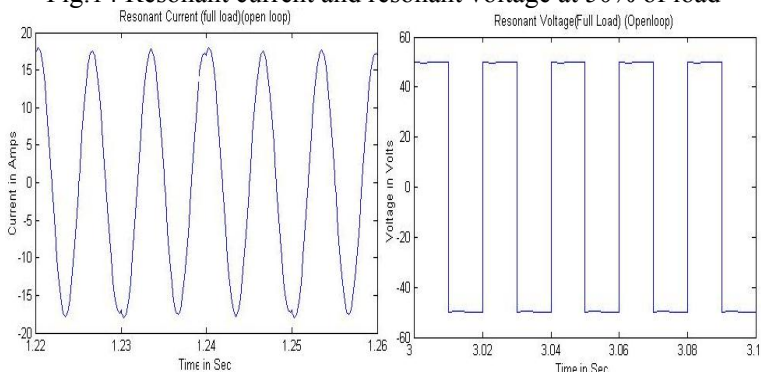

Fig.15 Resonant current and resonant voltage at $100 \%$ of load

The output voltages of the open loop LCL-T SPRC are shown in fig. 16 . Here the settling time 0.66 for $50 \%$ of load and 0.8 for $100 \%$ of load, the steady state error for $50 \%$ of load is 0.06 and $100 \%$ of load is 0.079 .
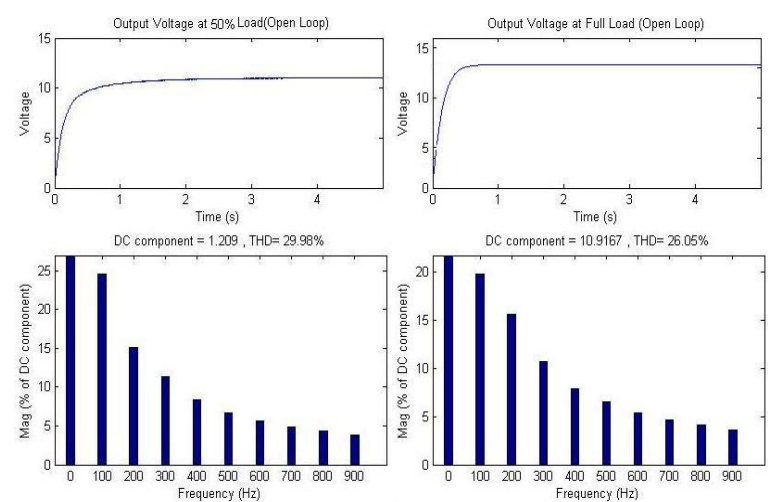

Fig.16. Output voltage and Harmonic Spectrum at 50\% and $100 \%$ of load (open loop)

\section{B. B.Closed Loop Response}

\section{PID Controller}

The response for a reference voltage of $10 \mathrm{~V}$ the output voltage is $12 \mathrm{~V}$.In the closed loop response by using PID Controller, the overshoot and settling time is less compared to open loop, and the response is oscillatory. The plots of resonant voltage resonant current, output voltage across load and measured THD values are shown in fig.18. With respect to Fig.16, the justified that settling time of output voltage in open loop controller is more than that of the settling time in PID controller which is depicted as shown in Fig.17-18.

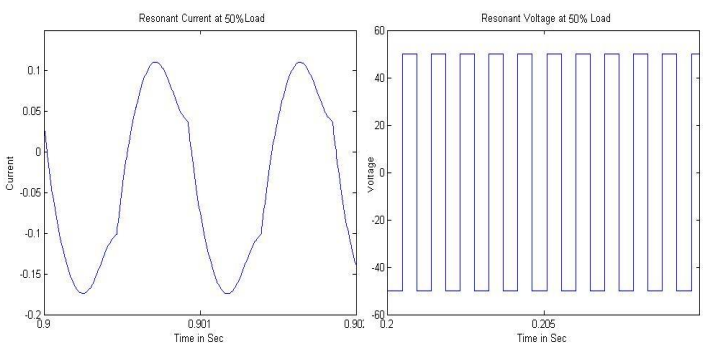

Fig.17 Resonant current and resonant voltage at $50 \%$ of load

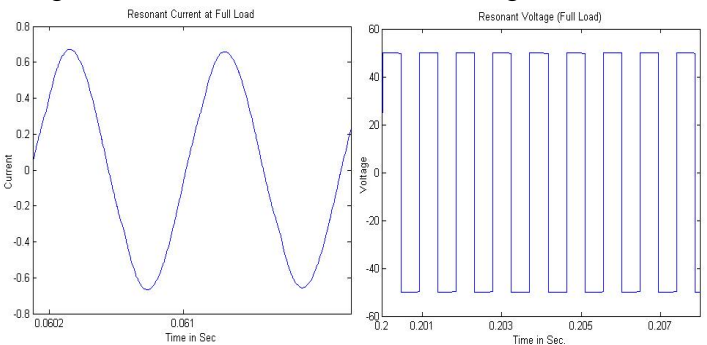

Fig. 18 Resonant current and resonant voltage at $100 \%$ of load

The voltage across $\mathrm{V}_{\mathrm{AB}}$ and primary current of the transformer are in shown in fig.17-18. The slight droop in the Resonant characteristics is due to the increase in conduction losses in the bridge inverter and resonant network. The output voltage of the LCL-T SPRC with PID controller are shown in Fig. 19, here the settling time 0.058 for $50 \%$ of load and 0.1 for $100 \%$ of load ,the steady state error for $50 \%$ of load is 0.06 and $100 \%$ of load is 0.079 .
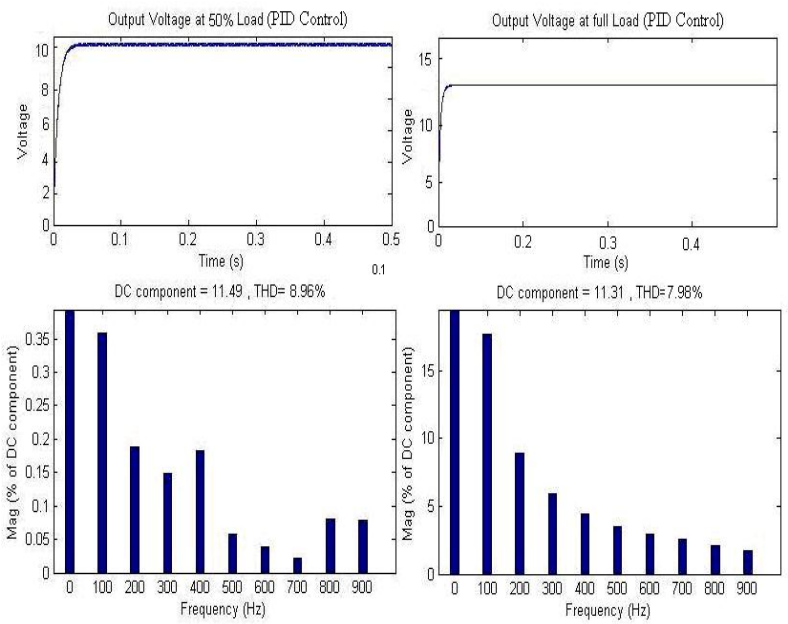

DC component $=11.31$, THD $=7.99 \%$

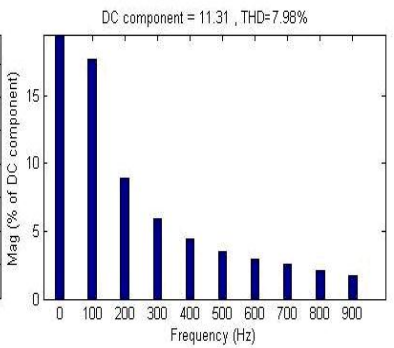

Fig. 19. Output voltage and Harmonic Spectrum at $50 \%$ and $100 \%$ of load (PID)

\section{Fuzzy Controller}

The response for a reference voltage of $10 \mathrm{~V}$ the output voltage is $12 \mathrm{~V}$.In the closed loop response by using Fuzzy Controller, the overshoot and settling time is less compared to open loop and PID controller, and the response is oscillatory. The plots of resonant voltage, resonant current, output voltage across load and measured values are shown in Fig.20-21.with different loads. 


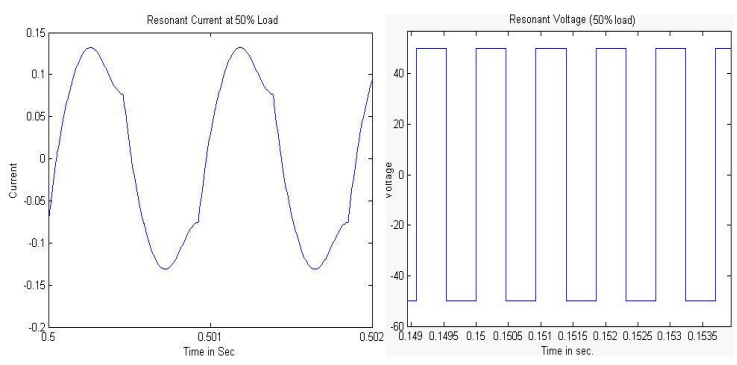

Fig.20 Resonant current and resonant voltage at $50 \%$ of load

The voltage across $\mathrm{V}_{\mathrm{AB}}$ and it is absorbed that primary current of the transformer are in Fig.18. We get the inverter output as pure square wave without any harmonics and with Resonance frequency.

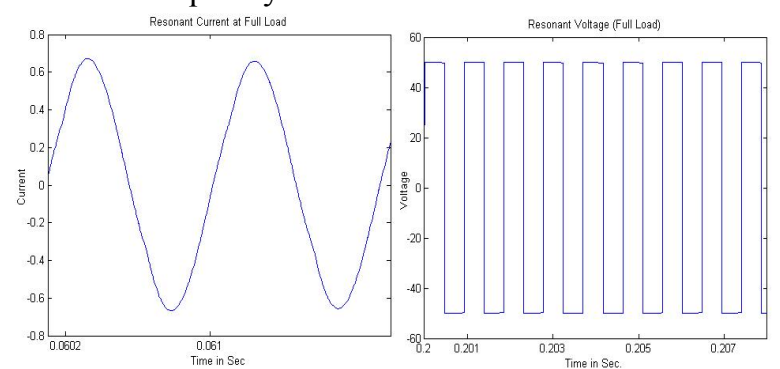

Fig. 21 Resonant current and resonant voltage at $100 \%$ of load

The inductor and capacitor are connected to the output of inverter for resonance purpose and it is used for impedance matching, current control. Another good feature of this converter is that the converter operation is not affected by the non idealities of the output transformer (magnetizing inductance) because of the additional resonance inductor $\mathrm{L}_{2}$. The output voltage is constant for any load variation.
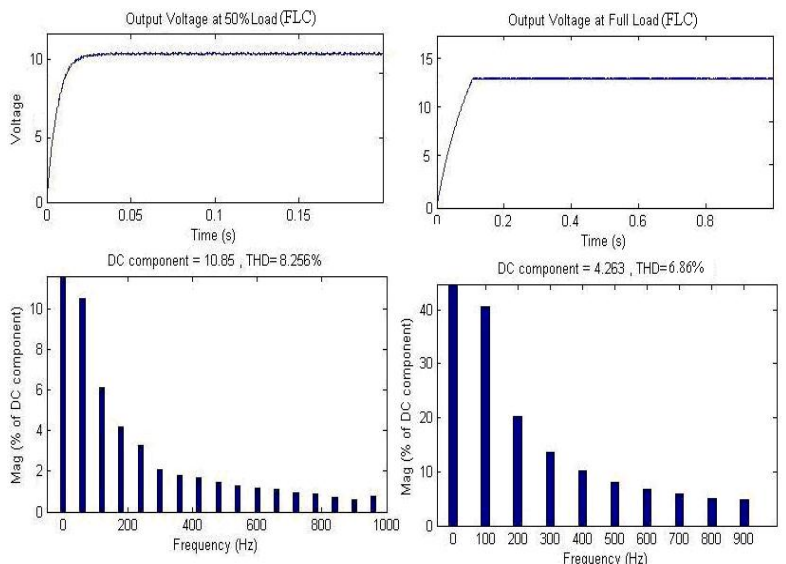

Fig.22 Output voltage and Harmonic Spectrum at $50 \%$ and $100 \%$ of load (FLC)

The Harmonic spectrum and AC component present in output voltage are very less compared to PID controller. The above Fig. 22 shows that the settling time 0.0358 for $50 \%$ of load and 0.07 for $100 \%$ of load, the steady state error for $50 \%$ of load is 0.0136 and $100 \%$ of load is 0.016 . The result is justified that settling time of output voltage in PID controller is more than that of the settling time in FLC. The output voltage response is flexible and sensitive.

\section{E. Performance Evaluation}

The open loop and closed loop for LCL-T SPRC have been estimated and provided in Table II. It is seen that the
PID/Fuzzy based closed loop controller provides better settling time. This ensures that the system can be controlled effectively.

As far concerned to Table II.It is obvious that the rise time and settling time of open loop and PID controller has been compared and concluded that Fuzzy has got better performance.

TABLE II.COMPARATIVE EVALUATION OF VARIOUS PERFORMANCES
\begin{tabular}{|l|c|c|c|c|}
\hline \multirow{3}{*}{ Controller } & \multicolumn{2}{|c|}{ Rise time in Sec. } & \multicolumn{2}{l|}{ Settling time in Sec } \\
\cline { 2 - 5 } & $\begin{array}{l}\mathrm{R}_{\mathrm{L}} \text { load } \\
(50 \%)\end{array}$ & $\begin{array}{c}\mathrm{R}_{\mathrm{L}} \mathrm{Load} \\
(100 \%)\end{array}$ & $\begin{array}{l}\mathrm{R}_{\mathrm{L}} \text { load } \\
(50 \%)\end{array}$ & $\begin{array}{c}\mathrm{R}_{\mathrm{L}} \mathrm{Load} \\
(100 \%)\end{array}$ \\
\hline Open loop & 0.4 & 0.52 & 0.66 & 0.8 \\
\hline PID & 0.04 & 0.059 & 0.058 & 0.1 \\
\hline Fuzzy & 0.026 & 0.057 & 0.0358 & 0.07 \\
\hline
\end{tabular}

The Harmonic Spectrum performance of both open loop and closed loop controller for $50 \%$ and $100 \%$ load condition is given in Table III

TABLE III.COMPARATIVE EVALUATION OF HARMONIC SPECTRUM PERFORMANCE

\begin{tabular}{|l|c|c|}
\hline \multirow{2}{*}{ Controller } & \multicolumn{2}{|c|}{ THD in \% } \\
\cline { 2 - 3 } & $\mathrm{R}_{\mathrm{L}}$ load (50\%) & $\mathrm{R}_{\mathrm{L}} \operatorname{Load}(100 \%)$ \\
\hline Open loop & 29.98 & 26.05 \\
\hline PID & 8.96 & 7.98 \\
\hline Fuzzy & 8.256 & 6.86 \\
\hline
\end{tabular}

From Table III it is clear that the THD is under safe limit in fuzzy controller compared with other controllers. The stead state error for open loop and closed loop controller for 50\% and $100 \%$ load are given in Table IV. In view of the results obtained and it is learnt that the Steady state error is reduced with the help of Fuzzy controller.

TABle IV. Comparative Evaluation of Steady State Performances

\begin{tabular}{|l|c|c|}
\hline \multirow{2}{*}{ Controller } & \multicolumn{2}{|c|}{ Steady state error } \\
\cline { 2 - 3 } & $\mathrm{R}_{\mathrm{L}}$ Load (50\%) & $\mathrm{R}_{\mathrm{L}}$ Load(100\%) \\
\hline Open loop & 0.06 & 0.079 \\
\hline PID & 0.058 & 0.03 \\
\hline Fuzzy & 0.0136 & 0.016 \\
\hline
\end{tabular}

\section{F. Rle Load For Different Controllers}

The output voltage at RLE load are plotted for open loop,PID and Fuzzy Logic controller and the performance is analysised.The qualitative analysis has been done merely by observation of shape of waveforms.

The response for a reference voltage of $100 \mathrm{~V}$ and output voltage is $100 \mathrm{~V}$, in the open loop response, the overshoot and the settling time are very high, and the response is oscillatory. The proposed control strategy is able to eliminate the peak overshoot and reduce the settling time. The output voltage at RLE load (open loop) and THD value are shown in Fig. 23. 

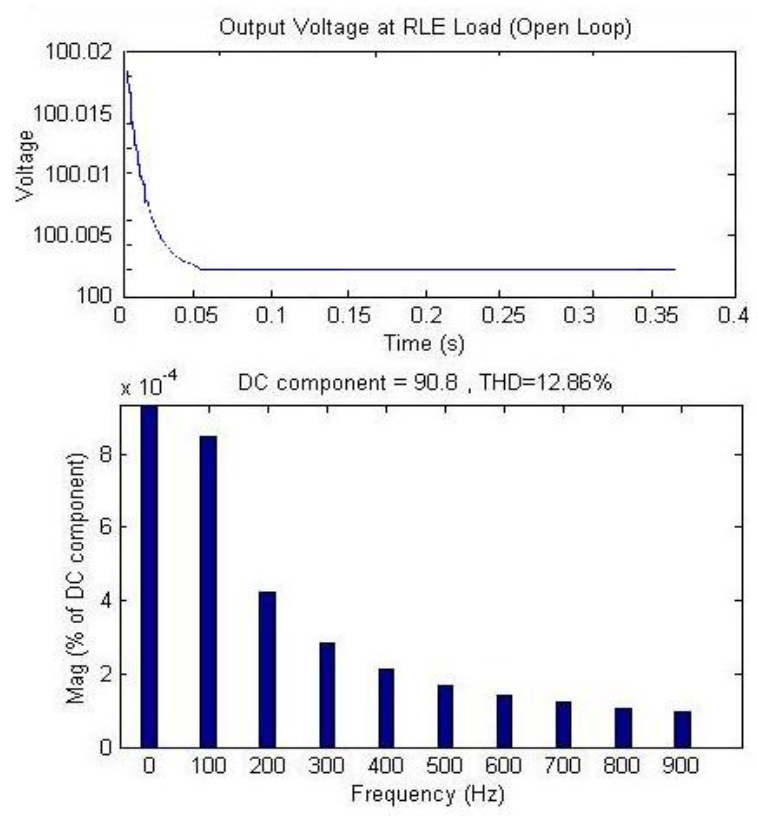

Fig.23. Output voltage and Harmonic Spectrum for RLE load (open loop)

From the response it is clear that the PID controller is ineffective in eliminating the overshoot, rise time and high frequency noise suppression. This happens because of several reasons. The integrator increases the system type number, thus minimizing the steady-state error. The additional phase delay introduced by the integrator tends to slow down the response. PID controllers help amplification of high frequency noise which is a serious drawback in switching converter applications. The output voltage across the RLE load by using PID controller are shown in Fig.24. From proposed closed loop controller the response it is inferred that the measurement overshoot and noise is highly suppressed by the Fuzzy controller, the DC component and THD Values are reduced and the regulated voltage of $100 \mathrm{~V}$ is obtained. The output voltage across the RLE load with Fuzzy controller are shown in Fig.25.
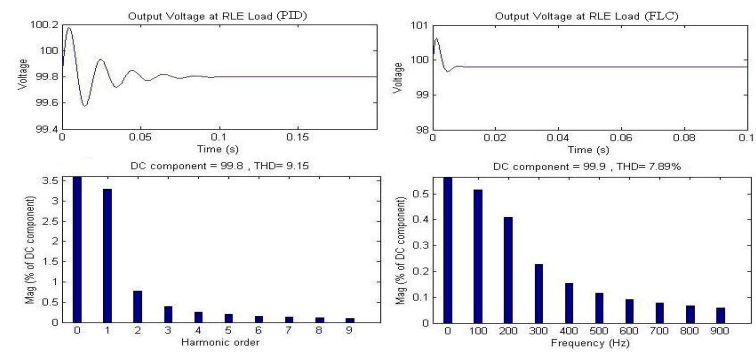

Fig.24 Output voltage and Harmonic Spectrum for RLE load (PID.FLC)

The output current fed RLE load with different controllers are presented in Fig.26. The load current value are reduced for open loop controller compared to another controller. In PID controller load current settling time and the rise time is high because of RLE load, This controller overshoot is very high in open loop controller where as the wave form is under damped in PID with more settling time. In FLC the wave shape is less overshoot and settling time is less compared to PID.

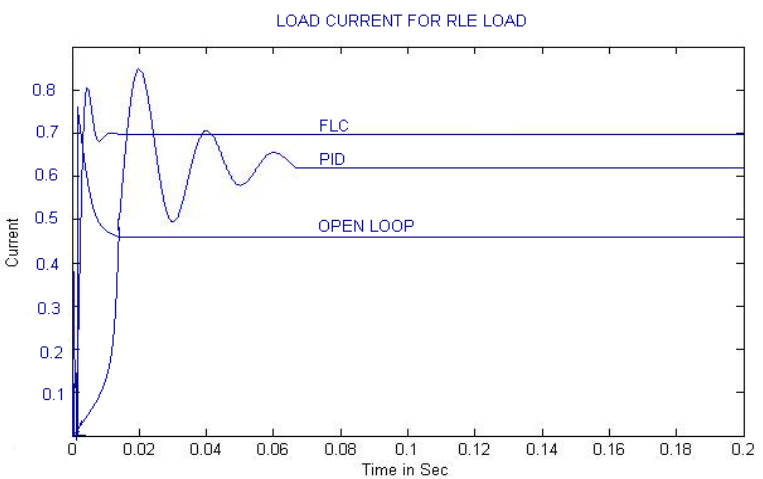

Fig.25Load current for RLE Load

From Table $\mathrm{V}$ it can be inferred that the settling time is 0.45 in sec. Max.\% over shoot is 1.05 for open loop, in PID controller the settling time is 0.12 in sec. Max.\% over shoot is 0.68 has been compared and concluded that Fuzzy has got better performance.

TABLE V.COMPARATIVE EVALUATION OF TRANSIENT AND STEADy STATE PERFORMANCES

\begin{tabular}{|l|c|c|c|}
\hline Controller & $\begin{array}{c}\text { Settling Time } \\
\text { in Sec }\end{array}$ & \% Over Shoot & $\begin{array}{c}\text { Steady state } \\
\text { error }\end{array}$ \\
\hline Open loop & 0.45 & 1.05 & 0.04 \\
\hline PID & 0.12 & 0.68 & 0.004 \\
\hline Fuzzy & 0.062 & 0.38 & 0.002 \\
\hline
\end{tabular}

The above table shows that the peak overshoot is eliminated and the settling time is much lower with the new control strategy. The measurement noise is highly suppressed and is much better than the PID controller.

TABLE VI. COMPARATIVE EVALUATION OF HARMONIC SPECTRUM

\begin{tabular}{|l|c|c|}
\multicolumn{3}{c}{ PERFORMANCE } \\
\hline Controller & THD \% & D.C. Component \\
\hline Open loop & 12.86 & 90.8 \\
\hline PID & 9.15 & 99.8 \\
\hline Fuzzy & 7.89 & 99.9 \\
\hline
\end{tabular}

The controllers are obtained the THD results and tabulated in Table VI.It is learnt that the Steady state error and THD values are reduced with the help of Fuzzy controller.

A plot of THD versus load value in percentage for FLC and PID are shown Fig.27. From the graph it is concluded that THD value is reduced to the lower values when compared to PID controller for different load values. 
THD Vs Load value in \%

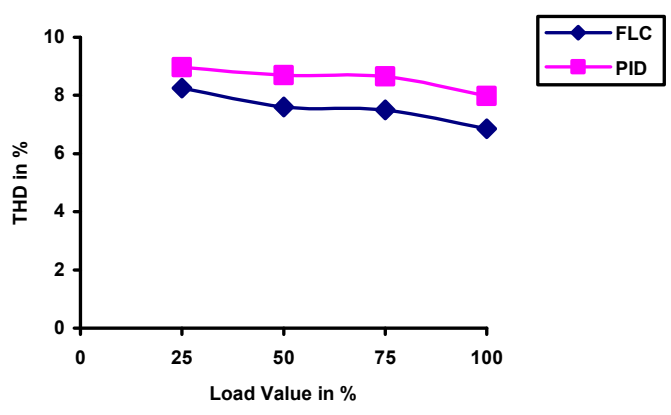

Fig.26 RL in value \% Vs THD in \%

The graph Fig.28. for output power versus Load current has been plotted which depicts that the power drawn decays steeply for lower load and as the load increases the power drawn gradually decreases and remain constant at greater loads. Among the three curves FLC is well defined

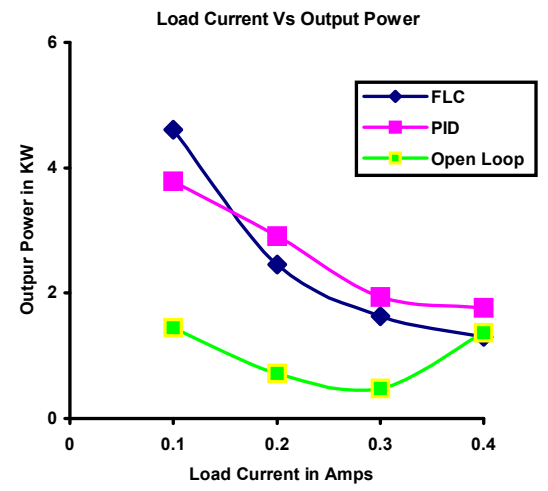

Fig.27Load Current Vs Output power

The above discussion the fuzzy Controller parameters are easy to determine. The proposed new control strategy the parametric and the load Sensitivity is much reduced. The results obtained indicate that the FLC is an effective approach for DC-DC converter output voltage regulation.

\section{CONCLUSION}

A FLC based LCL-T SPRC circuit has been simulated in MAT LAB/ Simulink and has been analyzed. This converter with a voltage type load and current type load shows it provides load independent operation, output voltage regulation. So, the switching power losses are minimized. The effectiveness of FLC as compared with PID Controller and open loop is verified by simulation studies. The LCL-T SPRC can be used for applications such as Space and radar high voltage power supplies with the appropriate turns ratio of HF transformer.

\section{REFERENCES}

[1] G.S.N.Raju and Seshagirirao Doradla, "An LCL Resonant converter with PWM Control Analysis, simulation, and Implementation”, IEEE Transactions On Power Electronics, vol.10, No.2 March 1995.

[2] A.K.S.Bhat, Analysis and Design of LCL-Type Series Resonant Converter,. IEEE INTELEC, pp172-178, (1994).

[3] Vijayakumar Belaguli, and Ashoka K. S. Bhat, "Series-Parallel Resonant Converter Operating in Discontinuous Current
Mode-Analysis, Design, Simulation, and Experimental Results," IEEE Transactions on Circuits and System-I: Fundamental Theory and Applications, vol. 47, no. 4, April 2000

[4] Mangesh Borage, Sunil Tiwari, and Swarna Kotaiah, "LCL-T Resonant Converter With Clamp Diodes:A Novel Constant-Current Power Supply With Inherent Constant-Voltage Limit" IEEE Transactions On Industrial Electronics, vol. 54, no. 2, april 2007.

[5] Mangesh Borage, Sunil Tiwari, and Swarna Kotaiah,"Analysis and Design of an LCL-T Resonant Converter as a Constant-Current Power Supply'IEEE Transactions On Industrial Electronics, vol. 52, no. 6, December 2005.

[6] Paolo Mattavelli,and Giorgio Spiazzi, “General-Purpose Fuzzy Controller for DC-DC Converters" IEEE Transactions On Power Electronics, VOL. 12, NO. 1, January 1997.

[7] J. M. Correa, F. A. Farret, "A Fuzzy-Controlled Pulse Density Modulation Strategy for a Series Resonant Inverter with Wide Load Range" IEEE Transactions On Power Electronics, VOL. 12, NO 1.pp $1650-1655,2003$

[8] T.S.Sivakumaran,S.P.Natarajan, "Development of Fuzzy Control of Series-ParallelLoaded Resonant converter-Simulation and Experimental Evaluation", Proceedings of India International Conference on Power Electronics 2006 ,pp 360-366.

[9] S. Arulselvi, Uma Govindarajan and v. Saminath, "Development Of Simple Fuzzy Logic Controller (Sflc) For Zvs Quasi-Resonant Converter: Design, Simulation And Experimentation" Indian institute of science. J. Indian inst. Sci., may-june 2006, vol 86, pp 215-23.

[10] S. Arulselvi, G. Uma, and M. Chidambaram, Design of PID controller for boost converter with RHS zero, IEEE-4th Int. Conf. on Power Electronics and Motion Control, Xi'an University, China, pp. 532-537 (2004).

[11] Kaithamalai Udhayakumar, Ponnus, "Hybrid Posicast Controller for a DC-DC Buck Converter" Serbian Journal Of Electrical Engineering Vol. 5, No. 1, May 2008, 121-138.

[12] A.K.S.Bhat "Analysis and Design of A Fixed-frequency LCL-Type Series Resonant Converter with Capacitive Output Filter," IEE PROC-Circuits Devices syst...Vol.144, No2, (April 1997).

[13] C.Nagarajan and M.Madhswaran, "Analysis and simulation of LCL series Resonant Full Bridge Converter using PWM technique with load independent operation" International Conference on Information and Communication Technology in Electrical Sciences (ICTES 2007), IET-UK.Vol.1.pp 190,Dec.2007.

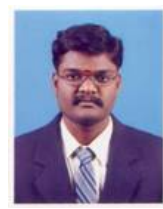

C.Nagarajan received the B.E degree from K.S.Rangasamy College of Technology, affiliated to Madras University, during 1997-2001, India, and the M.Tech degree from the Vellore Institute of Technology, Vellore, Tamilnadu India, in 2004. He is currently working towards his doctoral degree at Bharath Institute of Higher Education and Research (BIHER) University, Chennai, India. He has been a member of the faculty at Centre for Advanced Research, Muthayammal Engineering College, Rasipuram, Tamilnadu, India since 2005. His research interests include fuzzy logic and neural network applications to power electronics and drives .

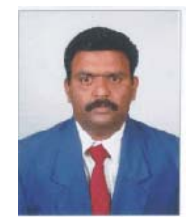

M.Madheswaran received the BE Degree from Madurai Kamaraj University in 1990, ME Degree from Birla Institute of Technology, Mesra, Ranchi, India in 1992, both in Electronics and Communication Engineering. He obtained his $\mathrm{PhD}$ degree in Electronics Engineering from the Institute of Technology,Banaras Hindu University, Varanasi, India, in 1999. At present he is a Principal of Muthayammal Engineering College, Rasipuram, India. He has authored over forty five research publications in international and national journals and conferences. His areas of interest are theoretical modeling and simulation of high-speed semiconductor devices for integrated optoelectronics application, Bio-optics and Bio-signal Processing. He was awarded the Young Scientist Fellowship (YSF) by the State Council for Science and Technology, TamilNadu, in 1994 and Senior Research Fellowship (SRF) by the Council of Scientific and Industrial Research (CSIR), Government of India in 1996. Also he has received YSF from SERC, Department of Science and Technology, Govt. of India. He is named in Marquis Who's Who in Science and engineering in the year 2006. He is a life member of IETE, ISTE and IE (India) and also a senior member of IEEE. 